\title{
Approaches to the Development of Human Health Toxicity Values for Active Pharmaceutical Ingredients in the Environment
}

\author{
Tamara L. Sorell ${ }^{1,2}$
}

\begin{abstract}
Received 23 November 2014; accepted 14 August 2015; published online 3 September 2015
Abstract. Management of active pharmaceutical ingredients (API) in the environment is challenging because these substances represent a large and diverse group of compounds. Advanced wastewater treatment technologies that can remove API tend to be costly. Because of the potential resources required to address API in the environment, there is a need to establish environmental benchmarks that can serve as targets for treatment and release. To date, there are several different approaches that have been taken to derive human health toxicity values for API. These methods include traditional risk assessment approaches that calculate "safe" doses using experimental data and uncertainty (safety) factors; point of departure (POD), which starts from a therapeutic human dose and applies uncertainty factors; and threshold of toxicological concern (TTC), a generic approach that establishes threshold values across broad classes of chemicals based on chemical structure. To evaluate the use of these approaches, each of these methods was applied to three API commonly encountered in the environment: acetaminophen, caffeine, and chlorpromazine. The results indicate that the various methods of estimating toxicity values produce highly varying doses. Associated doses are well below typical intakes, or toxicity thresholds cannot be derived due to a lack of information. No uniform approach can be applied to establishing thresholds for multiple substances. Rather, an individualized approach will need to be applied to each target API.
\end{abstract}

KEY WORDS: API; human health; PPCPs; toxicity values.

\section{INTRODUCTION}

In 1999, Daughton and Ternes identified risks associated with a group of nonconventional environmental pollutants derived from personal care products, human and veterinary pharmaceuticals, "nutraceuticals," fragrances, sunscreens, and numerous others, along with their metabolites and transformation products. They termed this diverse group of substances pharmaceuticals and personal care products, or PPCPs (1).

For decades, health-based limits through both airborne and direct contact routes of exposure have been derived specifically to protect workers in the pharmaceutical industry (2). Over the past 15 years, interest in PPCP exposure to the general public through environmental releases has expanded rapidly. A 2000 United States Geological Survey (USGS) study (3) called public attention to the issue of drugs and hormones in the environment with a landmark survey that identified wastewater contaminants in $80 \%$ of sampled stream

\footnotetext{
$\overline{{ }^{1} \text { Brown and Caldwell, One Tech Drive, Suite 310, Andover, }}$ Massachusetts 01810, USA.

${ }^{2}$ To whom correspondence should be addressed. (e-mail: tsorell@ brwncald.com)
}

sites. A companion study identified these types of contaminants in $81 \%$ of sampled groundwater sites in 18 states (4). In 2010, the New York City Department of Environmental Protection evaluated the occurrence of PPCPs in the city's water supply source waters and detected 14 of 72 targeted compounds (5). Concern is increasing globally, and the International Society of Doctors for the Environment has proposed "Environmentally persistent pharmaceutical pollutants" as an Emerging Policy Issue under the Strategic Approach to International Chemicals Management (6). In response, the German Federal Environment Agency has launched a multi-national research project; preliminary data indicate that PPCPs are found in all five global regions (56 countries) in surface water, groundwater, and drinking water (7). The updated United States Environmental Protection Agency (US EPA) database of PPCP-related information contains nearly 20,000 citations (8). In 2012, based on growing concerns about pharmaceuticals in drinking water, several US agencies signed a Memorandum of Understanding to collaborate and facilitate research on identifying chemicals for regulation under the Safe Drinking Water Act (9).

The US EPA has identified numerous pathways through which PPCPs and associated active pharmaceutical ingredients (API) are released to the environment, including usage and disposal by individuals, release of hospital wastes to sewage systems, private septic/leach fields, transfer of sewage 
solids to land, direct releases to open water (bathing, swimming, or aquaculture), industrial/manufacturing waste streams, and disposal to landfills (10). Wastewater treatment plants (via both effluent and sludge) have been identified as the primary release sources to the environment, as human excretion following therapeutic use is considered the principal pathway (11). However, conventional wastewater treatment, which relies on activated sludge, has variable and limited ability to remove these substances (12).

The management of API is challenging because these substances represent such a large and diverse group of compounds, the vast majority of which are approved for use and provide some benefit through usage to select populations for whom they are designated or prescribed. Efforts to reduce quantities of API manufactured and released through decreased usage "stewardship" efforts date back over a decade (13), and include a recent framework to influence prescribing practices by classifying API according to potential environmental persistence (14). However, over 10,000 prescription and over-the-counter pharmaceuticals are approved for usage (12), and this number excludes countless additional API in consumer and personal care products. Therefore, it is unlikely that release of API into the environment can be addressed solely via pollution prevention practices.

Advanced wastewater treatment technologies that can remove API tend to be costly. Effective treatment technologies, such as granular activated carbon (GAC), powdered activated carbon (PAC), reverse osmosis (RO), membrane bioreactor (MBR), ozonation, and nanofiltration, tend to be expensive in comparison or in addition to commonly used treatment processes (15), increasing treatment costs by anywhere from 1.4- to 6- or even 10-fold (ultraviolet filtration and reverse osmosis being the most costly; Menon, Rohan. Conversation with Tamara Sorell, 2015 Feb 13). In addition, combined sewer overflows (CSOs), which bypass treatment and discharge raw sewage to waterways, remain a large problem in urban areas. The cost of abating CSO pollution nationwide in the USA has been estimated in the tens of billions of dollars (16). Even characterization is expensive: the cost to analyze a sample for API can be as high as $\$ 1000$ (17).

Because of the potential resources required to address API in the environment, there is a need to establish environmental thresholds that can serve as targets for treatment and release. There are multiple endpoints of concern, including general human toxicity, human carcinogenicity, ecological toxicity, endocrine disruption, and antibiotic resistance. In the interest of narrowing a very large field of study, this evaluation focuses on human health noncarcinogenic toxic effects.

\section{Regulatory Drivers}

A number of investigators have developed screening approaches to setting human health toxicity values for API, but there is little precedent for establishing formal sets of regulatory guidelines. One exception is Australia, which has developed recycled water drinking water-based guidelines (ranging from 0.35 to $1050 \mu \mathrm{g} / \mathrm{L}$ ) that include chemicals classified as fragrances, antibiotics, non-steroidal anti-inflammatories, $\beta$-adrenergic blockers, estrogenic hormones, and general pharmaceuticals (18). The Netherlands has recently proposed surface water quality standards for four pharmaceuticals, considering the human health endpoints of use as a water supply and fish ingestion (19). New York State regulates organic compounds under the generic standards for principal organic contaminants $(50 \mu \mathrm{g} / \mathrm{L}$ for any single unspecified organic contaminant) (20). In the USA, the US EPA's Contaminant Candidate List 3 (CCL 3) is a list of contaminants that are known or anticipated to occur in public water systems and may require regulation in the future based on potential human health risk in drinking water (21). The CCL 3, released in 2009, includes nine hormones and one antibiotic (22). The draft CCL 4 list, released in February 2015, contains 20 chemicals that are pharmaceutical ingredients or involved in the production or formulation of PPCP products (23). While promulgation of US Federal drinking water standards in the near future is not expected, guidance values often serve as important precursors and may drive policy. For example, the US EPA has developed screening benchmarks for pesticide exposure (24). In 2013, the European Union added three pharmaceutical compounds to the "watch list" of emerging pollutants that could one day be placed on the priority list (25). These kinds of non-enforceable benchmarks can serve as precursors to regulatory standards.

\section{Approaches to Setting Human Health Toxicity Values}

The toxicity evaluation approaches identified to date have been useful in classifying API and generally characterizing the overall potential human health impacts of PPCPs in the environment. Most investigators have focused on comparing detected or modeled environmental concentrations or intakes to conservative health-based concentrations. These methods have largely been intended as screening tools, overly protective with a large margin of safety. The benchmarks developed have provided insight into ranking API for environmental significance and guiding further study, but are not necessarily appropriate for developing regulatory limits.

This paper describes the principal toxicity value-setting methods and illustrates how they might be used to derive limits for selected API. The principal methods used to date are described, and three API are evaluated using these various approaches to explore suitability for use in regulatory limit development.

Environmental concentrations in various media (soil, sediment, sludge, wastewater, etc.) that may correspond to a given human dose depend on a range of exposure and environmental transport variables (such as vegetative uptake, degradation, and amenability to treatment) that will vary depending on the setting and exposure scenario. For purposes of consistency, this paper describes exposures in terms of a standardized unit of dose measurement ( $\mathrm{mg} / \mathrm{kg}$-day). Drinking water equivalents are also provided.

\section{TOXICITY VALUE DEVELOPMENT METHODS}

A variety of methods have been used by investigators to establish health-based values for API. In many cases, there is overlap in terminology. For example, "acceptable daily intakes" have been derived from different methodologies, and any of several doses may serve as the "point of departure." Margins of exposure (MOEs) and predicted no-effect concentrations (PNECs) are similar concepts describing safe doses extrapolated 
from observed effects. The distinctions below are made simply to describe the principal approaches for further assessment.

\section{Acceptable Daily Intake}

The acceptable daily intake (ADI) is the identified amount of a chemical to which a person can be exposed on a daily basis over an extended period of time (usually a lifetime) without suffering a deleterious effect. ADIs for use in risk assessments are derived from no observed adverse effect levels (NOAELs) from human or animal studies, to which various safety factors are added. Safety factors, typically each a multiple of 10 , account for uncertainties from animal-to-human extrapolation, susceptibility of sensitive individuals, subchronic-to-chronic exposure extrapolation, and underlying data deficiencies (26). As a practical matter, therefore, the layering of safety factors can result in ADIs well below thresholds for adverse effects, in some cases by orders of magnitude.

\section{Reference Dose}

The reference dose (RfD) is an adaptation of the ADI used by the US EPA and serves as the principal risk assessment toxicity tool for evaluating toxic effects other than cancer and mutagenicity. The uncertainty factors (UFs) used by the US EPA in developing RfDs are 10-fold to extrapolate from a lowest observed adverse effect level (LOAEL) to a NOAEL; 10-fold to extrapolate from animal to human data, 10-fold to extrapolate from subchronic to chronic results; and 10-fold to protect sensitive human populations (26). The RfD approach also provides for an additional modifying factor (MF) in addition to uncertainty factors to address the identified uncertainties and deficiencies in ADIs, such as failure to consider the shape of the dose-response curve, selection of the appropriate adverse endpoint, and the strength of the underlying study, particularly the number of exposed individuals. The US EPA also provides a confidence (high, medium, or low) the evaluators have in the RfD and its likelihood to prevail in the future (26). Despite a more rigorous review of the data compared to the ADI, the RfD process is still very conservative and results in doses that may be many times below actual levels of concern. Conservatism is useful in screening and for ensuring protectiveness, but can present a challenge in risk management. In some cases, conservatively derived concentrations may be overprotective, resulting concentrations that are difficult or expensive to detect analytically, cannot be environmentally achieved, are based on intakes well below typical or voluntary exposures, or are otherwise unreasonably low.

\section{Clinical Point of Departure}

The term "point of departure" (POD) is used in the literature to define initial doses from various sources, including NOAELs or LOAELs as part RfD approaches. Rather than starting from a NOAEL (typically in an animal model), some investigators have estimated ADIs, MOEs, or PNECs starting with a pharmaceutical agent's therapeutic dose, or in some cases information from preclinical toxicology studies (27-29). This POD is then divided by the same safety factors used in the RfD process. Schwab et al. (30) developed a series of five uncertainty factors (UFs), to adjust for lowest to no-effect levels, exposure duration, inter-species extrapolation, individual sensitivity, and data quality. As applied, these UFs do not generally amount to a scaling of dose as high as with the RfD approach, but can in some cases be over 1000 or more (27).

To distinguish approaches, in this paper, the term "POD" applies specifically to clinical doses.

\section{Threshold of Toxicological Concern}

The threshold of toxicological concern (TTC) is a method of deriving generic ambient concentrations or intakes associated with negligible risk in the absence of toxicological data. This approach has been used to assess the confidence rating to the risks associated with low-level substances in the diet $(31,32)$, drinking water (33), and metabolites of plant protection products (pesticides) (34). It is equivalent to the threshold of regulation policy used by the US Food and Drug Administration (FDA) to establish a general food additive safety threshold of 0.5 parts per billion (ppb) (35). TTCs are generic concentrations based on toxicological information for broad categories of compounds, but can be tiered to account for varying chemical and toxicological properties (36). "Cramer" potency classes (37) have been used to classify organic chemicals based on structure progressing from a category with minimal potential for toxicity (class I) to compounds with structural features that do not allow a presumption of safety (class III) (34).

There are other methods of deriving toxicity values that do not fit neatly into one of the three major approaches summarized above. The Minnesota Department of Health (MDH), for example (38), describes 10 approaches, three of which they identify as applicable to noncarcinogenic effects of pharmaceuticals: TTC, lowest therapeutic dose approach (equivalent to the POD approach described above), and percentile approach (a generic method that develops generic advisory criteria). MDH has identified additional methods that may apply to non-pharmaceutical emerging contaminants of concern and to genotoxic and carcinogenic endpoints. As indicated above, this paper does not address those endpoints.

Of the universe of potential toxicity value derivation approaches, three of the prominent methods have been selected for further evaluation in this paper:

- Extrapolation starting with an observed or estimated noeffect level as the point of departure (RfD approach)

- Use of a clinical dose as the initial point of departure (POD)

- Generic approaches (TTC)

Toxicity values derived using these three approaches have been applied to the selected API as a tool to assess the utility and outcomes of the different methods.

\section{SELECTION OF API FOR EVALUATION}

For illustrative purposes, three API have been selected to represent a range of potential PPCP constituents. While there are risks and benefits associated with each API, they are intended to reflect a broad range of potential toxicity and 
usage. These API are then evaluated using the three identified approaches to derive toxicity values.

(1) Acetaminophen: Acetaminophen is the most commonly used pain reliever in the USA (39) and is a component of numerous over-the-counter (OTC) medications. It is the active ingredient in Tylenol ${ }^{\circledR}$. Due to its excellent safety profile and lack of significant side effects, it is the most widely prescribed analgesic agent in pediatric practice (40). This API is to represent a pharmaceutical that is generally considered safe at appropriate doses for virtually the entire population. However, liver toxicity at therapeutic dose has been reported (41).

(2) Chlorpromazine: Chlorpromazine, marketed in the USA as Thorazine, is a psychotropic medication. Although commonly prescribed worldwide and listed as an essential drug by the World Health Organization (42), chlorpromazine has serious and potentially irreversible side effects at therapeutic doses. Chlorpromazine is included here to represent a potentially hazardous pharmaceutical that has serious and idiosyncratic side effects, such as the neurological condition tardive dyskinesia (43).

(3) Caffeine: Caffeine (1,3,7-trimethylxanthine) occurs naturally in popular foods and beverages (such as coffee, tea, and chocolate) and is also a common food and medication additive. Over $60 \%$ of soft drinks sold in the USA contain caffeine (44). Caffeine is included to represent a substance that is widely ingested on a dietary basis.

The following section applies the three approaches for estimating toxicity values for each of these three API. The resulting toxicity values are summarized in Table I.

\section{API EVALUATIONS}

\section{Acetaminophen}

$R f D$. Acetaminophen has been studied in various animal models. Studies have reported chronic NOAELs in rats (200 $\mathrm{mg} /$ day for 28 weeks), as well as in rats, rabbits and dogs (50 to $400 \mathrm{mg} /$ day for 13 to 40 weeks). A dose of $300 \mathrm{mg} / \mathrm{kg}$-day for 32 weeks produced renal lesions in rats with induced renal infection (but not in healthy rats) (45). From this LOAEL, default US EPA UFs of 10 for LOAEL to NOAEL, 10 for interspecies extrapolation, and 10 for sensitive individuals would be applied. The derived RfD is $0.3 \mathrm{mg} / \mathrm{kg}$-day. Using the NOAEL of $400 \mathrm{mg} / \mathrm{kg}$-day and UFs of 10 for inter-species extrapolation, and 10 for sensitive individuals produces an RfD approximately an order of magnitude higher ( $4 \mathrm{mg} / \mathrm{kg}$-day).

Using human data, MDH (48) derived a lower chronic RfD (0.093 mg/kg-day) for acetaminophen based on a POD (therapeutic dose) of $27.8 \mathrm{mg} / \mathrm{kg}$-day and $70 \mathrm{~kg}$ body weight. MDH defined this dose (1950 mg/day) as the LOAEL based on increased serum liver enzymes, identified by McNeil in the Tylenol $^{\circledR}$ product information (42). MDH then applied a final UF of 300 (MDH cites UFs of 10 for intra-species variability, 3 for use of minimal LOAEL, 3 for use of subchronic human data for chronic duration, and 3 for database uncertainty). The European Agency for Veterinary Medicinal Products
(EMEA) (55) used the lowest observed effect level (LOEL) of $5 \mathrm{mg} / \mathrm{kg}$-day in infants with a safety factor of 100 to derive a human health ADI of $0.05 \mathrm{mg} / \mathrm{kg}$-day. Note that this LOEL is below the required therapeutic dose (for any age), and therefore, this approach is equivalent to an RfD approach rather than a clinical POD approach that starts with the therapeutic dose. The EMEA ADI was adopted by Australia in setting water guidelines.

$P O D$. The minimum therapeutic total daily dose for infants is $10 \mathrm{mg} / \mathrm{kg}$ (10 mg/kg-day) (56). Adding UFs based on Schwab et al.'s protocol of 3 for LOAEL to NOAEL, 3 for exposure duration, and 3 for individual variability derives a final ADI of $0.37 \mathrm{mg} / \mathrm{kg}$-day. Schwab et al. (30) evaluated this drug, and starting with the adult therapeutic total daily dose of $9.3 \mathrm{mg} / \mathrm{kg}$ (9.3 mg/kg-day) and applying a total UF of 27 (3 for LOAEL to NOAEL, 3 for exposure duration, and 3 for individual sensitivity) estimated a comparable ADI (0.34 mg/kg-day).

TTC. Mons et al. (33) developed drinking water guidelines for various categories of compounds using the TTC approach, and identified TTCs of 0.023, 0.0068, and $0.001125 \mathrm{mg} / \mathrm{kg}$-day (assuming a body weight of $80 \mathrm{~kg}$ ) for Cramer classes I, II, and III, respectively. Acetaminophen's Cramer classification would be III based on its aromatic structure (57). In setting water quality guidance values, Australia (18) has generally classified pharmaceuticals as Cramer class III, with a TTC of $0.0015 \mathrm{mg} / \mathrm{kg}$-day.

\section{Chlorpromazine}

$R f D$. Given how widely used chlorpromazine is, there is surprisingly little information in the literature on toxicity. Generally, this class of drugs (phenothiazines) has a high therapeutic index (indicating a large ratio between the toxic and pharmacological doses). The most dangerous toxic effects are related to hypersensitivity reactions (58), which cannot typically be evaluated on a dose-response basis. In fact, these drugs show a rather flat dose-response curve.

Side effects of chlorpromazine have been documented for well over 50 years (43). Some of these effects, such as dry mouth, could be viewed as relatively mild. However, chlorpromazine use is also associated with serious side effects at therapeutic doses. One of the most severe and disabling, tardive dyskinesia, is characterized by involuntary hyperkinetic movements, and may be irreversible. The risk of this disorder is dose dependent in the sense that it increases with duration of use, but there is considerable latency of onset as well as variable individual susceptibility, affecting an estimated one third of patients chronically exposed to anti-psychotic medications (59). Some attempts have been made to identify suitable animal models for studying tardive dyskinesia (59), but no toxicity values have been identified. Overall, it is not possible to derive a reliable RfD for this API. This conclusion was also reached by the European Agency for the Evaluation of Medicinal Products, which cited "the lack of relevant toxicological data, the longterm persistence of chlorpromazine in humans, and the probability that even small doses can cause behavioural change" 
(60). These observations regarding toxicity indicate that if environmental concentrations of chlorpromazine are in fact determined to be of concern, derivation of an RfD would be important.

POD. A precise dose-response curve for chlorpromazine has not been established, so doses vary. The recommended starting dose for a pediatric patient is approximately $0.55 \mathrm{mg} / \mathrm{kg}$ every 4 to $6 \mathrm{~h}(2.2 \mathrm{mg} / \mathrm{kg}$-day for four doses $)$; use of a 10-mg tablet four times a day in a $70-\mathrm{kg}$ adult would be $0.5 \mathrm{mg} / \mathrm{kg}$-day, although many regimens go far higher in all age groups (61). The onset of tardive dyskinesia is most commonly related to prolonged exposure and higher doses of anti-psychotic drugs, but it has been documented after brief treatment exposures at low doses (61). Because of the potential serious and irreversible nature of chlorpromazine's side effects at clinical doses, a POD approach that assumes safety at some identified fraction of the clinical dose cannot be determined, and may not be appropriate.

TTC. As indicated above, the TTC for Cramer class III chemicals is in the range of 0.0013 to $0.0015 \mathrm{mg} / \mathrm{kg}$-day. Mons et al. (33) identified an additional chemical class termed "nongenotoxic compounds" with a lower TTC, $0.00001875 \mathrm{mg} / \mathrm{kg}$ day (based on $0.0015 \mathrm{mg} /$ day for an $80-\mathrm{kg}$ person). Given the idiosyncratic nature of serious side effects, this drug could possibly be classified in this lower TTC category (the most conservative non-genotoxic category, which results in a final TTC 60 times lower than the low end of the Cramer class III range of $0.0013 \mathrm{mg} / \mathrm{kg}$-day).

\section{Caffeine}

$R f D$. Nawrot et al. (51) reviewed the literature on caffeine toxicity and recommended daily intake limits. Using the RfD approach and the LOAEL of $2.5 \mathrm{mg} / \mathrm{kg}$-day, this dose could be considered an acute LOAEL, and the following UFs would apply: 10 to extrapolate from acute to subchronic exposure, 10 to extrapolate from subchronic to chronic exposure, and 10 to protect sensitive individuals (assuming an additional modifying factor of 3 was not added). The final RfD would be $0.0025 \mathrm{mg} / \mathrm{kg}$-day, a very small dose in the same range as RfDs for known toxicants such as hexavalent chromium and potassium cyanide (54). For a $10-\mathrm{kg}$ child, this dose is the quantity of caffeine in $1 / 50$ th of a milliliter $(\mathrm{mL})$ of cola (based on the content of Coca-Cola, $35 \mathrm{mg}$ per $12 \mathrm{fl} \mathrm{oz}$ ).

Subchronic exposure data in rats indicate that exposure to approximately $40 \mathrm{mg} / \mathrm{kg}$-day in drinking water for 40 days had slight anorectic effects, especially in females, manifested as decreased consumption of sweet and salty snack foods (53). Using this dose as a chronic LOAEL, UFs of 10 for inter-species variability, 10 from subchronic to chronic, 10 from the LOAEL to the NOAEL, and 10 for sensitive individuals produces an $\mathrm{RfD}$ of $0.004 \mathrm{mg} / \mathrm{kg}$-day. The toxicity value derived this way is similar to the RfD based on human data.

$P O D$. Caffeine is added to numerous over-the-counter (OTC) medications as a headache remedy, up to $65 \mathrm{mg}$ per tablet (62). The therapeutic POD would be the typical adult dose (two tablets) from these formulations, $130 \mathrm{mg}$ (doses somewhat higher are found in formulations intended for stimulant effects; these are not considered here). Applying UFs based on Schwab et al.'s framework (30), 3 for NOAEL, 3 for exposure duration, 1 for species, 3 for individual sensitivity, and 1 for data quality, yields a total UF of 27. As indicated above, this UF is the same that the authors derived for relatively safe over-the-counter medications such as acetaminophen and ibuprofen. The final ADI using this approach and a body weight of $80 \mathrm{~kg}$ is $0.06 \mathrm{mg} / \mathrm{kg}$-day. This dose is equivalent to under $2 \mathrm{fl} \mathrm{oz}$ of cola.

TTC. The Australian drinking water guideline for caffeine is based on the TTC approach and has identified a threshold of $0.0015 \mathrm{mg} / \mathrm{kg}$-day (18). This TTC includes a safety factor of 1500 for substances classified as "threshold compounds" using a Cramer classification of III. If caffeine were classified as a Cramer II based on relatively little evidence of toxicity, the TTC would be higher $(0.009 \mathrm{mg} / \mathrm{kg}$-day $)$ but still a very small fraction of the typical daily US intake of $300 \mathrm{mg}$ (63) or $3.75 \mathrm{mg} / \mathrm{kg}$-day for an $80-\mathrm{kg}$ person.

\section{DISCUSSION}

\section{Evaluation of Approaches}

The evaluation of just three API clearly demonstrates that different approaches to setting human health-based toxicity values produce widely varying doses. Because of these ranges, any specific method could produce a toxicity value that is useful for screening but not necessarily reflective of actual risk, most likely in the direction of being overly conservative.

For acetaminophen, the POD approach produces the highest toxicity value of the three approaches described here. Given acetaminophen's excellent safety profile, this dose is potentially the most reasonable, but is still well below the level voluntarily ingested by millions of people. For caffeine, the POD method also derives the highest dose, which is clearly a very trace dose compared with typical voluntary ingestion rates.

Neither result produces a dose that is necessarily a reasonable basis for environmental management, primarily due to high UFs. In evaluating risks of pharmaceutical exposure to workers, lower UFs have been applied. However, these UFs do not consider sensitive subgroups that could be impacted by widespread environmental presence (2).

The POD approach has some similar limitations as the RfD approach, both of which assume that some fraction of a known dose poses no risk of adverse effects. Uncertainties have been handled through the application of multiple UFs, totaling as much as 1000 . While these high safety factors are likely to produce safe doses for screening, they generate low doses that have little practical meaning for risk management decisions. For example, Cunningham et al. (27) have identified an ADI for oncology drugs of $2.1 \mathrm{E}-06 \mathrm{mg} / \mathrm{kg}$-day. Using the standard assumptions for developing drinking water limits (US EPA estimates for body weight and water intake, currently $80 \mathrm{~kg}$ and $2.5 \mathrm{~L}$ per day (54)) and a relative source concentration (RSC) of 0.2 , this dose equates to a water concentration of $0.000013 \mathrm{mg} / \mathrm{L}(13 \mathrm{ng} / \mathrm{L})$. This level is likely 





to be detectable with current analytical methods for most compounds (see, for example, Furlong et al. (64)). However, regulating to trace concentrations may nonetheless present risk management challenges when broadly applied.

Chlorpromazine represents the other end of the spectrum of API: a drug generally used to treat serious medical conditions and associated with potentially unacceptable side effects at some unknown dose. There is insufficient information in the literature to support the estimation of an RfD for this drug. The absence of systematic studies for chlorpromazine may be due in part to the fact that this drug has been in use for over a half century; the availability of extensive human data reduces medical interest in animal models. Regardless, the idiosyncratic nature of the side effects and lack of appropriate animal models preclude the use of an RfD approach. Suitable data for an RfD approach may be similarly unavailable for many pharmaceuticals that have not been studied with the express purpose of identifying no-effect doses.

For API with potentially high toxicity, the TTC approach, although intended as a preliminary risk characterization step (49), offers a mechanism to identify de minimis levels of potentially highly toxic constituents. The proposed threshold doses for cytotoxic drugs are obviously very small, and environmental concentrations associated with this level of exposure and may present analytical challenges. Thus, this type of theoretical safe dose does not provide much input into environmental risk management, other than that any detectable quantity would be considered unacceptable. Thus, regulated final concentrations would functionally become reporting limits, which can provide a basis for guidance and regulation but are not very specific. As an alternative, "upstream" concentrations (such as in effluent) could be combined with modeling to predict final trace concentrations at receptor locations of concern.

Using a combined approach to identify toxicity values is challenging but possible. In developing recycled water quality guidelines, the Australian Natural Resource Management Ministerial Council (18) has applied a variety of approaches for individual substances, including generic thresholds based on Cramer classification, therapeutic doses, and NOAELs. Thus, these guidance values are derived using all three of the basic methods described in this paper. However, the Council also states that for certain highly toxic substances, individual risk assessments are required. The Council has relied to the extent possible on values published by other agencies, an approach that, if widely adopted, may eventually lead to a consensus regarding safe thresholds.

The Netherlands (19) also considered a variety of endpoints in the process of developing recommended surface water standards for four pharmaceuticals, including therapeutic dose, LOAEL/NOAEL, and epidemiologic data. Ultimately, ecological and not human health endpoints were used to recommended standards for three of these four compounds. The fourth had insufficient data and no recommendation was made. Absence of adequate toxicological information may limit development of toxicity factors for some API, and additional research may be required.

The evaluation of certain API is also complicated by beneficial effects. Daily acetaminophen use for 5 years or more has been reported to reduce the risk of prostate cancer, the second leading cancer type in men, by $38 \%$ (65). Caffeine also has documented beneficial effects, such as increased attention- related performance, which has also been observed at doses in children similar to those associated with anxiety (51). A chronic drinking water caffeine exposure study in rats, starting early in life, demonstrated the prevention of aging-related cognitive decline at doses in the range of $5 \mathrm{mg} / \mathrm{kg}$-day (66), comparable to the POD-derived toxicity value derived above. These observations go beyond hormesis, in which beneficial effects are observed at doses below which toxicity begins to emerge; rather, they indicate that certain API, including those commonly observed in the environment, may exert both positive and negative biological effects in the same dose range. Verherk (67) has illustrated this concept in describing risk analysis for four vitamins and minerals. Dosages of these supplements that are beneficial to a majority of people overlap with dosages that cause adverse effects on sensitive segments of the population. Thus, from a public health standpoint, it may be difficult to establish a meaningful health-based toxicity value for compounds that have beneficial effects.

It is not suggested here that involuntary environmental exposure to caffeine or any substance is desirable or should be disregarded as trivial. However, the Centers for Disease Control has estimated that humans are exposed to thousands of chemicals in the environment (68), through a multitude of pathways. The societal costs associated with managing API releases, such as widespread application of high-end treatment technologies, are potentially very large. There are also political and logistical barriers. These costs must be considered in the context of ubiquitous chemical exposures from all sources and meaningful estimates of risk reduction.

\section{Broader Context}

The evaluation presented here addresses only a single endpoint associated with API in the environment, namely human health noncarcinogenic toxic effects. Boxall et al. (69) used a "key question" approach to identify the priorities associated with PPCPs (API) in the environment. The top three issues were the significance of PPCP biological impacts in the natural environment relative to other chemical and nonchemical stressors; prioritization approaches for research; and the potential for the creation of antimicrobial-resistant organisms. Even within the realm of human health effects, endpoints of concern such as endocrine disruption and antibiotic resistance are not addressed by the methods considered in this review. The limitations of the evaluation presented here reflect the enormous complexity of this issue.

Of additional and even greater concern than human health endpoints are the ecotoxicological impacts, given that API tend to be released to the aquatic environment and are "captive to continual life-cycle, multigenerational exposure (1)." However, this concern does not necessarily mean that perceptions of human health risk will not ultimately drive API release regulation. "Outrage" (defined as "all the things that people are worried about that the experts ignore") has been responsible for most of the environmental laws over the past few decades (70), and outrage is commonly associated with public fears related to health. Thus, it is foreseeable that the identification of appropriate thresholds for human health may become critical in future policy regarding API even though ecological thresholds may be far lower. Furthermore, there are environmental pathways of exposure to API such as groundwater use and 
agricultural contamination from sewage sludge (71) that may primarily affect humans. For these reasons, it is important to develop reliable methods for setting human health as well as ecological thresholds.

The potential costs of managing API are very high and will likely be borne by taxpayers. To make appropriate costbenefit decisions as API move into the regulatory arena, doses and associated concentrations must be reasonable and attainable. Environmental standards and guidance values have generally been based on estimates of safe concentrations that are developed with large margins of safety (such as the RfD approach), or assuming infinitesimal cancer risks that are indistinguishable from background and are arbitrary in origin (72). The highly conservative nature of these thresholds, especially for organic compounds, is based in a large part on the premise that the chemicals under consideration are hazardous constituents that serve no beneficial exposure purpose and to which humans are involuntarily exposed. In fact, the current risk human health framework originated in 1984 with the Superfund Public Health Evaluation Manual, which was developed to address exposure to toxic contaminants released from hazardous waste sites (73). This document was the precursor to the US EPA's current Risk Assessment Guidance for Superfund (RAGS) guidance series (74). The methodology has been adopted globally and underlies major US environmental criteria such as the Safe Drinking Water Act and the Clean Water Act.

The use of these small risks in making hazardous site environmental decisions has become entrenched and is unlikely to change any time soon. However, alternative approaches can apply to API and may likely be necessary in order to manage costs. The tolerable level of risk is a matter of future public policy and debate; however, tiny hypothetical increases in risk may not provide suitable basis for regulation.

\section{Future Approaches}

Screening tools can provide an important initial step in API evaluation. The US EPA ToxCast research program is evaluating high-throughput screening (HTS) to prioritize chemicals for further study (75). The program is estimating exposure to a subset of the estimated 10,000 chemicals in commerce, including not only industrial chemicals and pesticides but also consumer product ingredients and pharmaceuticals. While this type of tool will not provide information to develop compound-specific guidance values, HTS may be of use in creating subsets of API that are candidates for further study.

Clinical data may provide some basis for identifying biological thresholds that are more realistic, or at least measurable. Use of pharmaceutical preclinical and clinical information has been identified as a priority in the arena of PPCP research (69). This type of approach will be limited to pharmaceuticals and is unlikely to provide useful data for thousands of consumer product-related chemicals. Caution must be used in extrapolating data from a population requiring a medication to the general population, and in particular sensitive individuals.

More nuanced and chemical specific approaches to developing UFs may be based on metabolic factors. Pathway-related UFs (considering processes such as conjugation, hydrolysis, and cytochrome P450) have been proposed and may allow metabolism to be integrated into health-based guidance value development (76). These approaches would require greater agency investment in the development of guidelines, but might produce guidelines that more closely reflect actual risks in human populations.

A number of studies globally have characterized API in environmental media and wastewater, as well as persistence and amenability to treatment $(3,12,29,50,77)$. Ultimately, management will need to focus on the compounds of both greatest prevalence and health concern. It will not be practical to assess or regulate large numbers of substances; rather, a subset of sentinel API compounds will ultimately need to be identified. For example, Khan and Nicell (77) have evaluated API based on a range of parameters. Initial selection included among other things consideration of dispensing practices, presence in Canadian surface water and finished drinking water supplies, and prioritization or study reported in other countries. Further evaluations considered measured and predicted environmental loading (using seven source terms) and toxicity, expressed as an ADI. ADIs were developed using a variety of approaches based on the type of compound. This screening process ultimately reduced the initial list of compounds by $96 \%$, to a manageable subset of 14 recommended for further study.

Identifying selected compounds in this way will make the evaluation and development of guidance values feasible even where a variety of toxicity approaches need to be applied.

\section{CONCLUSION}

Several methods are currently in use for identifying human health toxicity values for API. The application of three common approaches to example compounds illustrates the challenges that each of these methods poses. In developing strategies to establish toxicity values for multiple substances, a combination of approaches may be needed. Rather, following the use of screening methods to identify key target API compounds, an individualized approach will need to be applied to each target API.

While a tailored approach introduces complexity to the assessment process, it is most likely to provide input to make sound long-term risk management decisions on API in the environment.

\section{ACKNOWLEDGMENTS}

Thanks are extended to Jeffrey R. Caputi, PE, LSP, and Stephen Koenigsberg, $\mathrm{PhD}$, for a detailed review of the manuscript and to Rohan Menon for input regarding wastewater treatment costs.

\section{REFERENCES}

1. Daughton CG, Ternes TA. Pharmaceuticals and personal care products in the environment: agents of subtle change? Environ Health Perspect. 1999;107(6):907-38.

2. Alder AW, Kimmel TA, Sussman RG. Applying health-based risk assessments to worker and product safety for potent 
pharmaceuticals in contract manufacturing operations. Pharm Outsourcing. 2009;10:49-53.

3. Barnes KK, Kolpin DW, Meyer MT, Thurman EM, Furlong ET, Zaugg SD, et al. Water-quality data for pharmaceuticals, hormones, and other organic wastewater contaminants in U.S. streams, 1999-2000. Iowa City: U.S. Geological Survey (USGS); 2002. Open-File Report 02-94.

4. Barnes KK, Kolpin DW, Furlong ET, Zaugg SD, Meyer MT, Barber LB. A national reconnaissance of pharmaceuticals and other organic wastewater contaminants in the United States-I) groundwater. Sci Total Environ. 2008;402:192-200. doi:10.1016/ j.scitotenv.2008.04.028.

5. 2010 Occurrence of pharmaceutical and personal care products (PPCPs) in source water of the New York City water supply, pp. 24. New York (NY): New York City Department of Environmental Protection: 2011.

6. Pharmaceuticals in the Environment. Global occurrence, effects, and options for action. Germany. Umwelt Bundesamt. Federal Ministry for the Environment, Nature Conservation, Building and Nuclear Safety. Workshop Documentation. Geneva, Switzerland; 2014 April 8-9. 13 p. Available at: http://www.pharmaceuticals-inthe-environment.org/files/en/bereich_2/application/pdf/ workshop_documentation_global-relevance-of-pharmaceuticals-inthe-environment.pdf.

7. Ebert I, Silke H, Küster A, Kock-Jugl J, Weber FA, Bergmann A. Environmental relevance of pharmaceuticals: the global perspective. Nashville: Presented at: 34th Annual Meeting SETAC North America; 2013.

8. Daughton CG, Scuderi MST. Pharmaceuticals and personal care products (PPCPs): relevant literature [Internet]. 2008 [updated 2014 Oct 24; cited 2014 Nov 1]. U.S. Environmental Protection Agency, Las Vegas, NV. 2014. Available from: http://www.epa.gov/ppcp/lit.html.

9. U.S. Environmental Protection Agency, U.S. Department of Agriculture, U.S. Department of Health and Human Services, and U.S. Department of Interior. Memorandum of understanding on sustainability of federal collaboration on pharmaceuticals in drinking water; 2012.

10. Daughton, CG. Origins and fate of PPCPs in the environment [image on the Internet]. 2001 [updated $2001 \mathrm{Feb}$; cited 2014 Nov 1]. U.S. Environmental Protection Agency, Las Vegas (NV). Available from: http://www.epa.gov/ppcp/pdf/drawing.pdf.

11. Anderson PD, D'Aco VJ, Shanahan P, Chapra SC, Buzby ME, Cunningham VL, et al. Screening analysis of human pharmaceutical compounds in U.S. surface waters. Environ Sci Technol. 2004:38:838-49.

12. Jelić A, Gros M, Ginebreda A, Cespedes-Sánchez R, Ventura F, Petrovic M, et al. Occurrence, partition and removal of pharmaceuticals in sewage water and sludge during wastewater treatment. Water Res. 2011;45:1165-76. doi:10.1016/j.watres.2010.11.010.

13. Daughton CG. Cradle-to-cradle stewardship of drugs for minimizing their environmental disposition while promoting human health. I. Rationale for and avenues toward a green pharmacy. Environ Health Perspect. 2003;111:757-74. doi:10.1289/ehp.5947.

14. Daughton CG. Eco-directed sustainable prescribing: feasibility for reducing water contamination by drugs. Sci Total Environ. 2014;493:392-404. doi:10.1016/j.scitotenv.2014.06.013.

15. Lubliner, B, Redding, M, Ragsdale, D. Pharmaceuticals and personal care products in municipal wastewater and their removal by nutrient treatment technologies. Olympia (WA): Washington State Department of Ecology; 2010, 230 p. Publication Number.: 10-03-004. Available from: www.ecy.wa.gov/biblio/ 1003004.html.

16. Environmental Services. Environmental fact sheet. Available from: http://des.nh.gov/organization/commissioner/pip/factsheets/ wwt/documents/web-9.pdf.

17. FAQs about PPCPs: Montana focus [fact sheet]. Montana Department of Environmental Quality; 2008 Aug 8. Available from: http:// deq.mt.gov/wqinfo/swp/Guidance/PPCPs_final_Aug'08\%20_2_pdf.

18. Australian guidelines for water recycling: managing health and environmental risks (phase 2). Augmentation of drinking water supplies. Environment Protection and Heritage Council. Health and Medical Research Council. Natural Resource Management Ministerial Council; 2008.

19. Moermond CTA. Derivation of WFD water quality standards for carbamazepine, metoprolol, metformin and amidotrizoic acid.
The Netherlands: National Institute for Public Health and the Environment; 2014, RIVM Letter Report 270006002, 54 p. Available from: http://www.rivm.nl/en/Documents and_publications/Scientific/Reports/2014/juli/Environmental_ risk_limits_for_pharmaceuticals_Derivation_of_WFD_water_quality_standards_for_carbamazepine_metoprolol_ metformin_and_amidotrizoic_acid.

20. Fact sheet: frequently asked questions on pharmaceutical \& personal care products (PPCPs). New York City Department of Environmental Protection. New York (NY); [2014; cited 2014 Nov 1]. Available from: http://www.nyc.gov/html/dep/html/ drinking_water/ws_ppcp_faq.shtml\#Q6.

21. Fact sheet: final third drinking water contaminant candidate list (CCL 3). U.S. Environmental Protection Agency; [2009; cited 2014 Nov 1]. Available from: http://water.epa.gov/scitech/ drinkingwater/dws/ccl/upload/fs_cc3_final.pdf (fact sheet).

22. Drinking water contaminant candidate list 3-final. Fed Regist. 2009 Sep 21;74:51850-51862. Available from: https:// www.federalregister.gov/articles/2009/10/08/E9-24287/drinkingwater-contaminant-candidate-list-3-final.

23. Draft CCL 4 Chemical contaminants. http://www2.epa.gov/ccl/ chemical-contaminants-ccl-4.

24. Human health benchmarks for pesticides. U.S. Environmental Protection Agency; accessed 15 Feb 2015. Available from: http:// iaspub.epa.gov/apex/pesticides/f?p=HHBP:home.

25. European Parliament. Surface waters: 12 new controlled chemicals, three pharmaceuticals on watch list; 2013. Available from: http://www.europarl.europa.eu/news/en/pressroom/content/20130701IPR14760/.

26. Reference dose (RfD): description and use in health risk assessments. Background Document 1A. U.S. Environmental Protection Agency; 15 Mar 1993. Available from: http://www.epa.gov/iris/rfd.htm.

27. Cunningham VL, Binks SP, Olson MJ. Human health risk assessment from the presence of human pharmaceuticals in the aquatic environment. Regul Toxicol Pharmacol. 2009;53:39-45. doi:10.1016/j.yrtph.2008.10.006.

28. Cunningham VL, Perino C, D'Aco VJ, Hartmann A, Bechter B. Human health risk assessment of carbamazepine in surface waters of North America and Europe. Regul Toxicol Pharmacol. 2010;56:343-51. doi:10.1016/j.yrtph.2009.10.006.

29. Sanderson H. Presence and risk assessment of pharmaceuticals in surface water and drinking water. Water Sci Technol. 2011;63:2143-8. doi:10.2166/wst.2011.341.

30. Schwab BW, Hayes EP, Friori JM, Mastrocco FJ, Roden NM, Cragin D. Human pharmaceuticals in US surface waters: a human health risk assessment. Regul Toxicol Pharmacol. 2005:42:296-312. doi:10.1016/j.yrtph.2005.05.005.

31. Barlow S. Threshold of toxicological concern (TTC). A tool for assessing substances of unknown toxicity present at low levels in the diet. Washington: International Life Sciences Institute; 2005. 37 p.

32. Renwick AG. Structure-based thresholds of toxicological concern-guidance for application to substances present at low levels in the diet. Toxicol Appl Pharmacol. 2005;207:S585-91. doi:10.1016/j.taap.2005.01.034.

33. Mons MN, Heringa MB, van Genderen J, Puijker LM, Brand W, van Leeuwen CJ, et al. Use of the threshold of toxicological concern (TTC) approach for deriving target values for drinking water contaminants. Water Res. 2013;47:1666-78. doi:10.1016/ j.watres.2012.12.025.

34. Melching-Kollmuß S, Dekant W, Kalberlah F. Application of the "threshold of toxicological concern" to derive tolerable concentrations of "non-relevant metabolites" formed from plant protection products in ground and drinking water. Regul Toxicol Pharmacol. 2010;56:126-34. doi:10.1016/j.yrtph.2009.09.011.

35. Food additives; threshold of regulation for substances used in food-contact articles. Fed Regist. 1995;60:36582-36596.

36. Cheeseman MA, Machuga EJ, Bailey AB. A tiered approach to threshold of regulation. Food Chem Toxicol. 1999;37:387-412.

37. Cramer GM, Ford RA, Hall RL. Estimation of toxic hazard-a decision tree approach. Food Cosmet Toxicol. 1978;16:255-76.

38. Stevens JP. Drinking water contaminants of emerging concern program, Special project: evaluating, testing, and reporting of alternative risk assessment methods. Selection, evaluation and recommendations of viable alternative risk assessment methods for the development of drinking water guidance values. St. Paul: 
Minnesota Department of Health. Contaminants of Emerging Concern (CEC) Program. Environmental Health Division; 2012.

39. Greenlaw, E. OTC pain relief: understanding acetaminophen [internet]. 2010 [cited 2014 Nov 01]. Available from: http:// www.webmd.com/drug-medication/otc-pain-relief-10/pain-relievers-acetaminophen.

40. American Medical Association. Module 6 pain management. Pediatric pain management. Continuing medical education [Internet]. June 2013 [cited 2014 Nov 1]. Available from: http:// ama-cmeonline.com/pain_mgmt/module06_2012/.

41. James L, Sullivan JE, Roberts D. The proper use of acetaminophen. Paediatr Child Health. 2011;16:544-547. http:// www.ncbi.nlm.nih.gov/pmc/articles/PMC3223888/.

42. Adams, CE, Awad, GA, Rathbone, J, Thornley, B, SoaresWeiser, K. Chlorpromazine versus placebo for schizophrenia (review). In: The Cochrane Library, Issue 1.John Wiley \& Sons, Ltd; 2014.

43. Glaser EM, Newling PSB. Side effects of chlorpromazine hydrochloride. Br J Pharmacol. 1955;10:429-33.

44. Keast RSJ, Riddell LJ, Hall RL. Caffeine as a flavor additive in softdrinks. Appetite. 2007;49:255-9. doi:10.1016/j.appet.2006.11.003.

45. Acetaminophen [professional product information]. McNeil Consumer Healthcare; 2010.

46. Kolpin DW, Furlong ET, Meyer MT, Thurman EM, Zaugg SD, Barber LB, et al. Pharmaceuticals, hormones, and other organic wastewater contaminants in U.S. streams, 1999-2000: a national reconnaissance. Environ Sci Technol. 2002;36:1202-11. doi:10.1021/es011055j.

47. Lin AY, Tsai Y. Occurrence of pharmaceuticals in Taiwan's surface waters: impact of waste streams from hospitals and pharmaceutical production facilities. 2009; 407:3793-3802. doi: 10.1016/j.scitotenv.2009.03.009.

48. Toxicological summary for: acetaminophen. Minnesota Department of Health. St. Paul; 2014 Aug. 16 p. Available from: www.health. state.mn.us/divs/eh/risk/guidance/dwec/sumacetamin.pdf.

49. Kroes R, Kleiner J, Renwick A. The threshold of toxicological concern concept in risk assessment. Toxicol Sci. 2005;86:226-30. doi:10.1093/toxsci/kfi169.

50. Ebert I, Hein A. Pharmaceuticals in the environment-a first compilation of German monitoring data, 8 p. Federal Environment Agency; 2013.

51. Nawrot P, Jordan S, Eastwood J, Rotstein J, Hugenholtz A, Feeley M. Effects of caffeine on human health. Food Addit Contam. 2003;20:1-30. doi:10.1080/0265203021000007840.

52. Gardinali PR, Zhao X. Trace determination of caffeine in surface water samples by liquid chromatography-atmospheric pressure chemical ionization-mass spectrometry (LC-APCIMS). Environ Int. 2002;28:521-8.

53. Pettenuzzo LF, Noschang C, Toigo EV, Fachin A, Vendite E, Dalmaz C. Effects of chronic administration of caffeine and stress on feeding behavior of rats. Physiol Behav. 2008:95:295301. doi:10.1016/j.physbeh.2008.06.003.

54. Regional screening levels. US Environmental Protection Agency, Office of Research and Development [Internet]. [updated 2014 May; cited 2014 Oct 31]. Available from: http://www.epa.gov/ reg3hwmd/risk/human/rb-concentration_table/Generic_Tables/ index.htm.

55. The European Agency for the evaluation of medicinal products. Paracetamol. Summary Report;. Committee for Veterinary Medicinal Products; 1999 Feb. EMEA MRL/551/ 99-FINAL.

56. Kochanowski B. Acetaminophen OTC dosing for children. Consumer Health Products Association [slides]. 2011.

57. Lapenna S, Worth A. Analysis of the Cramer classification scheme for oral systemic toxicity-implications for its implementation in Toxtree. European Union. European Commission Joint Research Centre Institute for Health and Consumer Protection. 2011 EUR 24898 EN - 2011. Available from: http:// www.jrc.ec.europa.eu/ laboratories-research/predictive_toxicology/ doc/EUR_24898_EN.pdf. 39 p.

58. Chlorpromazine (PIM 125). [Internet]. International Programme on Chemical Safety. Cited 2014 Oct 12. Available from: http:// www.inchem.org/documents/pims/pharm/chlorpro.htm\# SectionTitle:2.1 Main risks and target organs.
59. Blanchet PJ, Parent MT, Rompré PH, Lévesque D. Relevance of animal models to human tardive dyskinesia. Behav Brain Funct. 2012;8:12. doi:10.1186/1744-9081-8-12.

60. Chlorpromazine. Summary report. Committee for Veterinary Medicinal Products. The European Agency for the Evaluation of Medicinal Products. 1996; EMEA MRL/111/96-FINAL.

61. Thorazine (chlorpromazine) drug information: warnings and precautions-prescribing information at RxList. [homepage on the Internet]. [updated 2014; cited 2014 Oct 12]. Available from: http://www.rxlist.com/thorazine-drug/warnings-precautions.html.

62. Migraines \& Headaches Health Center. [Internet] [updated 2014; cited 2014 Oct 31] Available from: http://www.webmd.com/ migraines-headaches/guide/triggers-caffeine.

63. Somogyi LP. Caffeine intake by the U.S. population. Prepared for The Food and Drug Administration and Oakridge National Laboratory, 90 p. 2010.

64. Furlong ET, Noriega M, Kanagy L, Coffey LJ, Burkhardt MR. Determination of human-use pharmaceuticals in filtered water by direct aqueous injection-high-performance liquid chromatography/ tandem mass spectrometry: U.S. Geological Survey techniques and methods, book 5, chap. B10, 49 p. 2014. doi.org/10.3133/tm5B10.

65. Jacobs EJ, Newton CC, Stevens VL, Gapstur SM. A large cohort study of long-term acetaminophen use and prostate cancer incidence. Cancer Epidemiol Biomark Prev Publ Am Assoc Cancer Res. 2011;7:1322-8. doi:10.1158/1055-9965.EPI-11-0210.

66. Vila-Luna S, Cabrera-Isidoro S, Vila-Luna L, Juárez-Díaz I, BataGarcía JL, Alvarez-Cervera FJ, et al. Chronic caffeine consumption prevents cognitive decline from young to middle age in rats, and is associated with increased length, branching, and spine density of basal dendrites in ca1 hippocampal neurons. Neuroscience. 2012;202:384-95. doi:10.1016/j.neuroscience.2011.11.053.

67. Verherk RHJ. The paradox of overlapping micronutrient risks and benefits obligates risk/benefit analysis. Toxicology. 2010;278:27-38. doi:10.1016/j.tox.2010.02.011.

68. Fourth national report on human exposure to environmental chemicals. Atlanta : Centers for Disease Control and Prevention; 2009.

69. Boxall ABA, Rudd MA, Brooks BW, Caldwell DJ, Choi K, Hickmann S, et al. Pharmaceuticals and personal care products in the environment: what are the big questions? Environ Health Perspect. 2012. doi:10.1289/ehp.1104477.

70. Sandman PM. Responding to community outrage: strategies for effective risk communication. American Industrial Hygiene Association; 2012. Available from: http://psandman.com/media/ RespondingtoCommunityOutrage.pdf.

71. Jones-Lepp TL, Stevens R. Pharmaceuticals and personal care products in biosolids/sewage sludge-the interface between analytical chemistry and regulation. Las Vegas, NV: US Environmental Protection Agency, Office of Research and Development, National Exposure Research Laboratory, Washington, DC: Office of Water, Office of Science and Technology, 2006. doi 10.1007/s00216-006-0942-z.

72. Kelly KE. The myth of $10^{-6}$ as a definition of acceptable risk. Vancouver: Proceedings of the 84th Annual Meeting Air \& Waste Management Association; 1991.

73. Superfund public health evaluation manual. Washington, DC: US Environmental Protection Agency, Office of Emergency and Remedial Response; 1984. EPA 540/1-86/060. OSWER Directive 9285-4.1.

74. Risk assessment guidance for superfund. Human Health Evaluation Manual 1989 et seq., Volume I. Washington, DC: US Environmental Protection Agency, Office of Emergency and Remedial Response; 1984. EPA 540/1-89/002.

75. Wambaugh JF, Setzer RW, Reif DM, Gangwal S, MitchellBlackwood J, Arnot JA, et al. High-throughput models for exposure-based chemical prioritization in the ExpoCast project. Environ Sci Technol. 2013;47:8479-88. doi:10.1021/es400482g.

76. Dorne JLCM, Walton K, Renwick AG. Human variability in xenobiotic metabolism and pathway-related uncertainly factors for chemical risk assessment and review. Food Chem Toxicol. 2005;43:203-16. doi:10.1016/j.fct.2004.05.011.

77. Khan, Nicell. Human health relevance of pharmaceutically active compounds in drinking water. In: PhACs in the environment: sources, risks, trade-offs and sewer epidemiology. 2014. Submitted for publication. 